\title{
AXIN2-Associated Adenomatous Colorectal Polyposis
}

\author{
Bruno Augusto Alves Martins ${ }^{1,2}$ Reinaldo Falluh Filho ${ }^{3(-)}$ Romulo Medeiros de Almeida ${ }^{1,2}$ \\ Renata Lazari Sandoval2 ${ }^{2}$
}

1 Serviço de Coloproctologia, Hospital Universitário de Brasília, Brasília, DF, Brazil

${ }^{2}$ Hospital Sírio-Libanês, Brasília, DF, Brazil

3 Unidade de Gastroenterologia, Instituto de Gestão Estratégica de

Saúde do Distrito Federal (IGESDF), Brasília, DF, Brazil

J Coloproctol 2021;41(4):443-446.

\begin{abstract}
Address for correspondence Bruno Augusto Alves Martins, MD, MSc, SQN 212, Bloco B, apto. 205, Brasília, DF, 70864-020, Brazil (e-mail: brunomartins.coloprocto@gmail.com).
\end{abstract}

\begin{abstract}
Keywords

- adenomatous polyposis coli

- axin protein

- intestinal polyposis

Introduction Most cases of colorectal cancer (CRC) occur sporadically; however, $\sim 3 \%$ to $6 \%$ of all CRCs are related to inherited syndromes, such as Lynch syndrome and familial adenomatous polyposis (FAP). The adenomatous polyposis coli (APC) and mutY DNA glycosylase (MUTYH) germline mutations are the main genetic causes related to colorectal polyposis. Nevertheless, in many cases mutations in these genes have not been identified. The aim of the present case report is to describe a rare case of genetic colorectal polyposis associated with the axis inhibition protein 2 (AXIN2) gene.

Case Report The first colonoscopy screening of a 61-year-old male patient with no known family history of CRC revealed $\sim 50$ colorectal polyps. A histological evaluation of the resected polyps showed low-grade tubular adenomas. Germline genetic testing through a multigene panel for cancer predisposition syndromes revealed a pathogenic variant in the AXIN2 gene. In addition to colorectal polyposis, the patient had mild features of ectodermal dysplasia: hypodontia, scant body hair, and onychodystrophy. Discussion The AXIN2 gene acts as a negative regulator of the Wnt/ $\beta$-catenin signaling pathway, which participates in development processes and cellular homeostasis. Further studies are needed to support the surveillance recommendations for carriers of the AXIN2 pathogenic variant.
\end{abstract}

\section{Introduction}

Colorectal cancer (CRC) represents the fourth most deadly cancer worldwide. ${ }^{1}$ It generally occurs sporadically; however, $\sim 3 \%$ to $6 \%$ of all CRCs are related to inherited syndromes. ${ }^{2,3}$ Lynch syndrome and familial adenomatous polyposis (FAP) are the two most common cancer predisposition syndromes associated with a higher risk of developing CRC. ${ }^{4}$

received

October 19, 2020

accepted after revision

March 22, 2021

published online

August 13, 2021
Familial adenomatous polyposis is an autosomal dominant genetic syndrome caused by highly-penetrant germline mutations in the adenomatous polyposis coli (APC) gene. Its major feature is the development of more than 100 colorectal adenomas during the second decade of life, with a near $100 \%$ risk of progression to CRC at an average age of 35 to 40 years. The presence of 10 to 99 synchronous adenomas in the large
DOI https://doi.org/ $10.1055 / \mathrm{s}-0041-1732328$ ISSN 2237-9363. (c) 2021. Sociedade Brasileira de Coloproctologia. All rights reserved.

This is an open access article published by Thieme under the terms of the Creative Commons Attribution-NonDerivative-NonCommercial-License, permitting copying and reproduction so long as the original work is given appropriate credit. Contents may not be used for commercial purposes, or adapted, remixed, transformed or built upon. (https://creativecommons.org/ licenses/by-nc-nd/4.0/)

Thieme Revinter Publicações Ltda., Rua do Matoso 170, Rio de Janeiro, RJ, CEP 20270-135, Brazil 
bowel is considered a milder phenotypic variant of FAP, and is also known as attenuated FAP. ${ }^{5-7}$

The main differential diagnosis of attenuated FAP is mutY DNA glycosylase (MUTYH)-associated polyposis. However, less than $50 \%$ of cases of attenuated polyposis are explained by APC and MUTYH mutations, suggesting the role of additional genes in the pathophysiological process. ${ }^{8}$ The advent of large-scale germline and somatic next-generation sequencing (NGS) provided new insight into the missing information on the heritability of these cases. ${ }^{9}$ It has been shown that adenomatous colonic polyposis may also be associated with polymerase proofreading-associated polyposis caused by mutations in the polymerase delta 1 (POLD1) and polymerase epsilon (POLE) genes, as well as mutS homolog 3 (MSH3) and nth like DNA glycosylase 1 (NTHL1) polyposis. ${ }^{10}$ Nevertheless, many cases remain as adenomatous polyposis of unknown etiology.

Germline mutations in the axis inhibition protein 2 (AXIN2) gene have been reported in some familial cases of gastrointestinal polyposis and ectodermal dysplasia. ${ }^{11,12}$ This gene encodes a scaffold protein of the $\beta$-catenin destruction complex, an important negative regulator of the Wnt/ $\beta$-catenin signaling pathway, which participates in cell proliferation, cytometaplasia, migration, apoptosis, and other cell functions. ${ }^{13,14}$

We herein present a rare case of AXIN2-related colorectal polyposis with ectodermal dysplasia.

\section{Case Report}

A 61-year-old man was referred by a clinician for colonoscopy due to a positive fecal occult blood test. The patient had never been submitted to a colonoscopy, and reported no symptoms. His medical history was significant for systemic arterial hypertension and tobacco exposure. He was the only son of a nonconsanguineous healthy couple. The family history of cancer showed only one second-degree family member with uterine cancer at more than 50 years of age.

Colonoscopy revealed $\sim 50$ polyps of varying sizes (from $1 \mathrm{~mm}$ to $15 \mathrm{~mm}$ ) and shapes distributed across all colonic and rectal segments (-Fig. 1). Some of the largest polyps were removed with a snare, and a histological evaluation revealed low-grade tubular adenomas.

Despite a non-expressive family history of cancer, the patient was referred to genetic counselling. The clinical geneticist requested a next-generation sequencing (NGS) multigene panel with genes related to known hereditary colorectal polyposis syndromes. A pathogenic variant (c.1966C > T, p. Arg656*) in the AXIN2 gene was identified. This sequence change creates a premature translational stop signal (p. Arg656*) in the AXIN2 gene. It is expected to result in an absent or disrupted protein product. This variant is not present in population databases (no frequency according to the Exome Aggregation Consortium [ExAC] database) ,and has been reported in a family with hypodontia and colorectal cancer and in isolated cases of hypodontia. ${ }^{12,15}$

Additional clinical findings were represented by congenital absence of some teeth (-Fig. 2), scant body hair, and onychodystrophy (-Fig. 3 ).

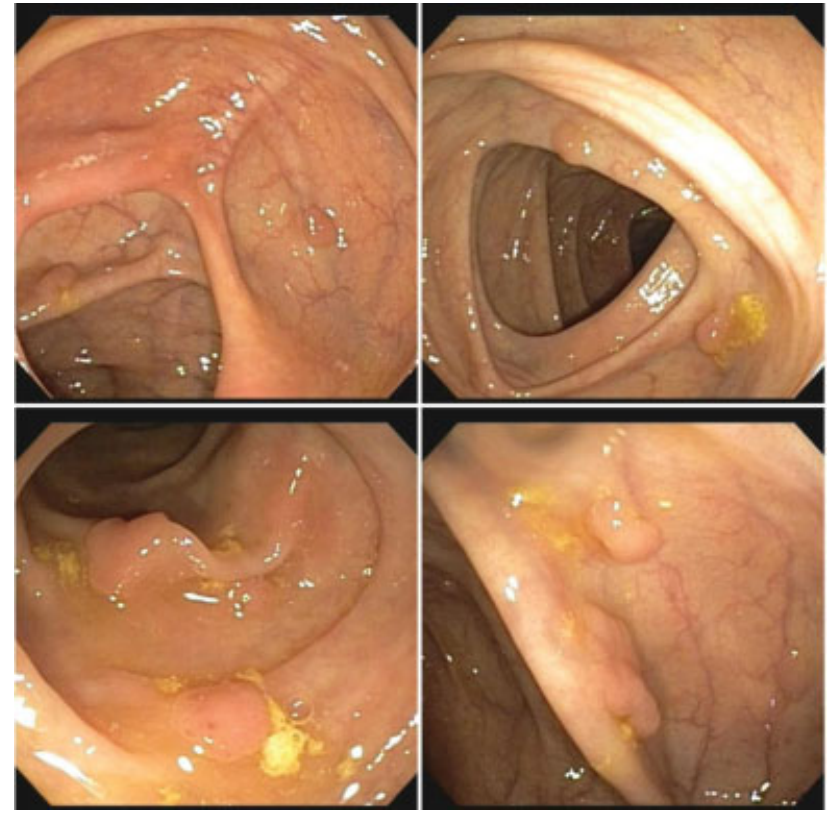

Fig. 1 Colonoscopy images showing multiple polyps.

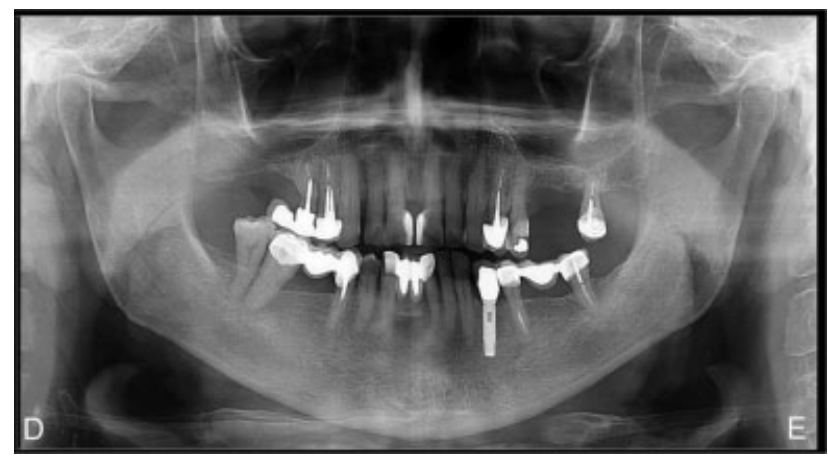

Fig. 2 Panoramic radiograph indicating congenitally-missing permanent teeth.

Three subsequent colonoscopies were performed to achieve complete resection of all polyps. Polyps smaller than $3 \mathrm{~mm}$ were resected with a biopsy forceps, and sessile polyps from $4 \mathrm{~mm}$ to $9 \mathrm{~mm}$ and stalked lesions were removed with snare polypectomy. Mucosectomy was applied for larger polyps and flat lesions. The patient remains asymptomatic, and undergoes regular endoscopic follow-up.

\section{Discussion}

The canonical Wnt signaling pathway is involved in development processes and cellular homeostasis in adult tissues through the regulation of the transcription of target genes. Somatic mutations affecting the elements of this pathway are associated with carcinogenesis, especially in colorectal and hepatic tumors. Beta-catenin levels play an essential role in this signaling pathway, translocating to the nucleus and binding to T-cell factor/lymphoid enhancer factor (TCF/LEF) transcription factors. The cytoplasmic component AXIN2 acts as a negative regulator of Wnt signaling by inducing the degradation of $\beta$-catenin. ${ }^{16,17}$ 

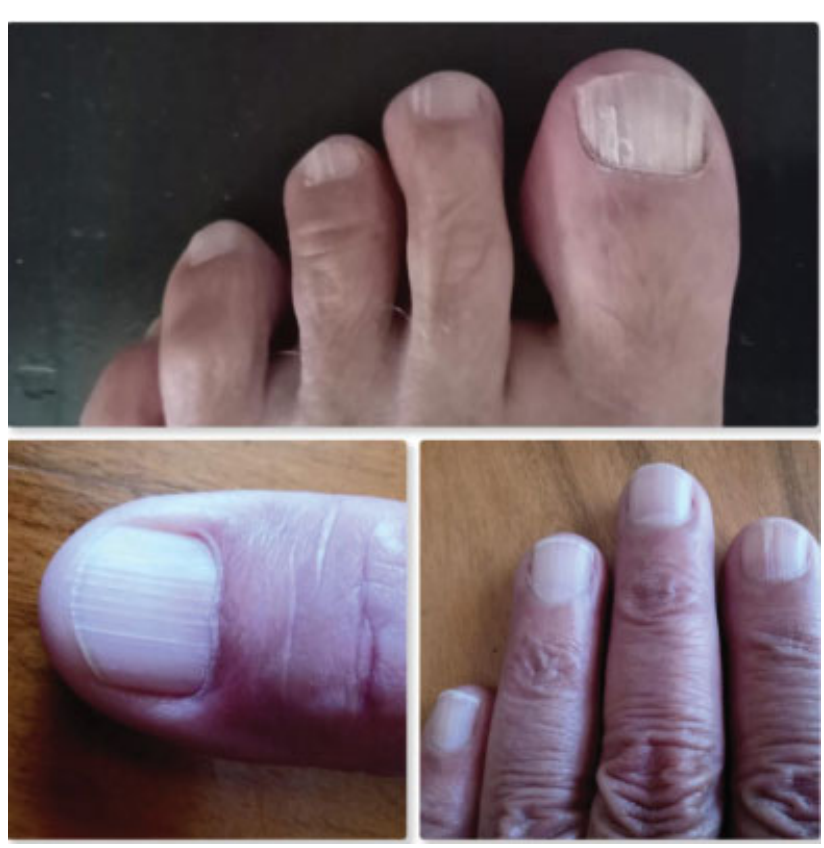

Fig. 3 Images demonstrating longitudinal ridging and splitting of the toenails and fingernails.

Recently, AXIN2 mutations have been associated with colorectal polyposis and oligodontia. ${ }^{8,11,12,18,19}$ Lammi et al. ${ }^{12}$ (2004) identified an AXIN2 mutation in a four-generation Finnish family, in which eleven members presented oligodontia, and eight had CRC or precancerous lesions of variable types. Marvin et al. ${ }^{18}$ (2011) described a family with an inherited AXIN2 mutation (c.1989G $>$ A) presenting an autosomal dominant pattern with manifestations of oligodontia and other findings, such as gastrointestinal polyps, a mild ectodermal dysplasia phenotype with sparse hair and eyebrows, and early onset CRC and breast cancers. In 2014, Rivera et al. ${ }^{11}$ found an AXIN2 germline variant (c.1387C > T) in one family with attenuated FAP. Carriers of this variant exhibited a variable number of polyps, but had no signs of ectodermal dysplasia. Ectodermal dysplasia includes a large and heterogeneous group of hereditary diseases characterized by clinical manifestations related to alterations in ectodermal structures, such as hair, nails, teeth, and skin. In the present case, the patient had hypodontia, sparse body hair without involvement of the scalp and eyebrows, and onychodystrophy.

To date, the guidelines recommend that carriers of AXIN2 mutations initiate colonoscopic surveillance between the ages of 25 and 30 years, with subsequent colonoscopies every 2 to 3 years if no polyps are identified. If polyps are found, the recommendation is to repeat the colonoscopy every 1 to 2 years. A surgical approach must be considered if the polyp burden becomes uncontrollable by colonoscopy. ${ }^{20}$

The present report reiterates the importance of AXIN2 mutations in the development of adenomatous polyposis. Further investigations are required to clarify the role of AXIN2 pathogenic variants in cancer risk and phenotypic expression, thus contributing to more appropriate CRC prevention strategies.

\section{Consent}

Informed consent was obtained from the patient for publication of this case report and accompanying images. The present study was approved by the Institutional Ethics Committee.

\section{Funding Statement}

This research did not receive any specific grant from funding agencies in the public, commercial, or non-profit sectors.

\section{Conflict of Interests}

The authors have no conflict of interests to declare.

\section{References}

1 Brody H. Colorectal cancer. Nature 2015;521(7551):S1-S1. Doi: 10.1038/521S1a

2 Ma H, Brosens LAA, Offerhaus GJA, Giardiello FM, de Leng WWJ, Montgomery EA. Pathology and genetics of hereditary colorectal cancer. Pathology 2018;50(01):49-59. Doi: 10.1016/j.pathol.2017. 09.004

3 Jasperson KW, Tuohy TM, Neklason DW, Burt RW. Hereditary and familial colon cancer. Gastroenterology 2010;138(06):2044-2058. Doi: $10.1053 /$ j.gastro.2010.01.054

4 Rosty C. The Role of the Surgical Pathologist in the Diagnosis of Gastrointestinal Polyposis Syndromes. Adv Anat Pathol 2018;25 (01):1-13. Doi: 10.1097/PAP.0000000000000173

5 Half E, Bercovich D, Rozen P. Familial adenomatous polyposis. Orphanet J Rare Dis. 2009;4:22 Published 2009 Oct 12. Doi: 10.1186/1750-1172-4-22

6 Galiatsatos P, Foulkes WD. Familial adenomatous polyposis. Am J Gastroenterol 2006;101(02):385-398. Doi: 10.1111/j.15720241.2006.00375.X

7 Roncucci L, Pedroni M, Mariani F. Attenuated adenomatous polyposis of the large bowel: Present and future. World J Gastroenterol 2017;23(23):4135-4139. Doi: 10.3748/wjg.v23.i23.4135

8 Lejeune S, Guillemot F, Triboulet J-P, et al; PAFNORD Group. Low frequency of AXIN2 mutations and high frequency of MUTYH mutations in patients with multiple polyposis. Hum Mutat 2006; 27(10):1064-1064. Doi: 10.1002/humu.9460

9 Basso G, Bianchi P, Malesci A, Laghi L. Hereditary or sporadic polyposis syndromes. Best Pract Res Clin Gastroenterol 2017;31 (04):409-417. Doi: $10.1016 / j . b p g .2017 .05 .011$

10 Palles C, Cazier J-B, Howarth KM, et al; CORGI Consortium WGS500 Consortium. Germline mutations affecting the proofreading domains of POLE and POLD1 predispose to colorectal adenomas and carcinomas. Nat Genet 2013;45(02):136-144. Doi: 10.1038/ng.2503

11 Rivera B, Perea J, Sánchez E, et al. A novel AXIN2 germline variant associated with attenuated FAP without signs of oligondontia or ectodermal dysplasia. Eur J Hum Genet 2014;22(03):423-426. Doi: 10.1038/ejhg.2013.146

12 Lammi L, Arte S, Somer M, et al. Mutations in AXIN2 cause familial tooth agenesis and predispose to colorectal cancer. Am J Hum Genet 2004;74(05):1043-1050. Doi: 10.1086/386293

13 Li S, Wang C, Liu X, Hua S, Liu X. The roles of AXIN2 in tumorigenesis and epigenetic regulation. Fam Cancer 2015;14 (02):325-331. Doi: 10.1007/s10689-014-9775-7

14 Wu Z-Q Brabletz T, Fearon E, et al. Canonical Wnt suppressor, Axin2, promotes colon carcinoma oncogenic activity. Proc Natl Acad Sci U S A 2012;109(28):11312-11317. Doi: 10.1073/ pnas.1203015109

15 van den Boogaard M-J, Créton M, Bronkhorst Y, et al. Mutations in WNT10A are present in more than half of isolated hypodontia 
cases. J Med Genet 2012;49(05):327-331. Doi: 10.1136/jmedgenet-2012-100750

16 Lustig B, Jerchow B, Sachs M, et al. Negative feedback loop of Wnt signaling through upregulation of conductin/axin2 in colorectal and liver tumors. Mol Cell Biol 2002;22(04):1184-1193. Doi: 10.1128/MCB.22.4.1184-1193.2002

17 Mazzoni SM, Fearon ER. AXIN1 and AXIN2 variants in gastrointestinal cancers. Cancer Lett 2014;355(01):1-8. Doi: 10.1016/j. canlet.2014.09.018

18 Marvin ML, Mazzoni SM, Herron CM, Edwards S, Gruber SB, Petty EM. AXIN2-associated autosomal dominant ectodermal dysplasia and neoplastic syndrome. Am J Med Genet A 2011;155A(04): 898-902. Doi: 10.1002/ajmg.a.33927

19 Wong S, Liu H, Bai B, et al. Novel missense mutations in the AXIN2 gene associated with non-syndromic oligodontia. Arch Oral Biol 2014;59(03):349-353. Doi: 10.1016/j.archoralbio. 2013.12.009

20 Gupta S, Provenzale D, Regenbogen SE, et al. NCCN Guidelines Insights: Genetic/Familial High-Risk Assessment: Colorectal, Version 3.2017. J Natl Compr Canc Netw 2017;15(12):1465-1475. Doi: $10.6004 /$ jnccn.2017.0176 